\title{
Is risedronate or alendronate more effective at preventing nonvertebral fractures in women with osteoporosis?
}

Dennis M Black and Clifford J Rosen

Nature Clinical Practice Rheumatology (2007) 3: 378-379 [doi:10.1038/ncprheum0530]

doi:10.1038/ncprheum0563

\section{CORRIGENDUM}

Due to an author miscommunication, the statement published in the above article "The authors have declared they have no competing interests." is incorrect. DM Black has received honoraria from Merck and Nycomed, and research support from Novartis. He has also acted as a consultant for Roche. CJ Rosen declared he has no competing interests.

\section{Don't miss the following articles that will soon be appearing in the pages of Nature Clinical Practice Rheumatology:}

\section{VIEWPOINT}

Why is the management of fibromyalgia syndrome so difficult for rheumatologists?

Elizabeth Scarbrough and Leslie J Crofford

\section{PRACTICE POINTS}

Anti-TNF switching: effect on outcomes in patients with RA Nancy Olsen

The clinical impact of neuropsychiatric manifestations in early systemic lupus erythematosus Gabor G IIlei

\section{REVIEWS}

The changing epidemiology of gout

Edward Roddy, Weiya Zhang and Michael Doherty

Primer: establishing a clinical trial unit-obtaining studies and patients

Roy Fleischmann

Primer: epigenetics of autoimmunity

Bruce Richardson

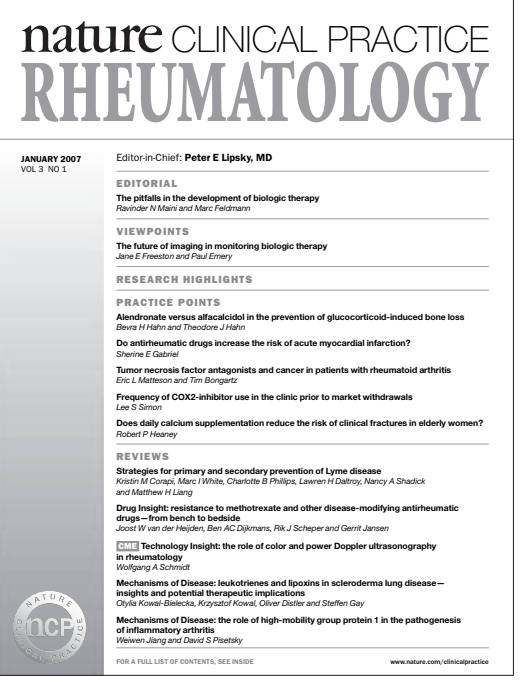

Please note that the title details are not finalized and might be subject to change. 